\title{
Publisher Correction: A visual tool for defining reproducibility and replicability
}

Prasad Patil, Roger D. Peng and Jeffrey T. Leek (D)

Correction to: Nature Human Behaviour https://doi.org/10.1038/s41562-019-0629-z, published online 17 June 2019.

In the version of this article initially published, the icon of the analyst was omitted from the key in Fig. 1. The error has been corrected in the HTML and PDF versions of the article.

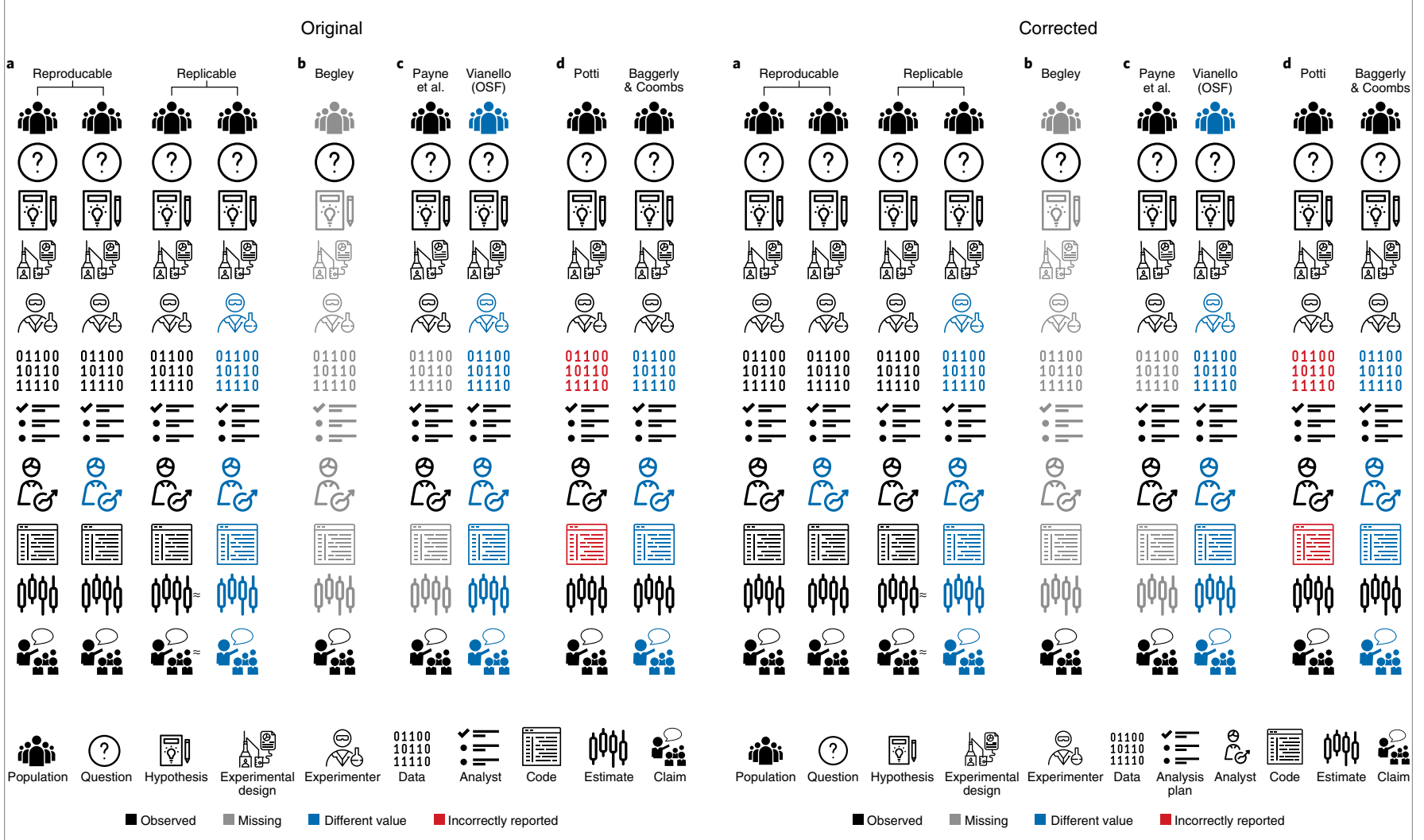

Fig. 1 | Original and corrected.

Published online: 29 July 2019

https://doi.org/10.1038/s41562-019-0706-3 